\title{
The first reported case of human tick paralysis in Brazil: a new induction pattern by immature stages
}

\author{
Almeida RAMB (1), Ferreira MA (2), Barraviera B (1, 3), Haddad Jr V (4)
}

(1) Department of Tropical Diseases, Botucatu Medical School, São Paulo State University (UNESP - Univ Estadual Paulista), Botucatu, São Paulo State, Brazil; (2) Undergraduate Program in Medicine, Botucatu Medical School, São Paulo State University (UNESP - Univ Estadual Paulista), Botucatu, São Paulo State, Brazil; (3) Center for the Study of Venoms and Venomous Animals, São Paulo State University (UNESP - Univ Estadual Paulista), Botucatu, São Paulo State, Brazil; (4) Department of Dermatology, Botucatu Medical School, São Paulo State University (UNESP - Univ Estadual Paulista), Botucatu, São Paulo State, Brazil.

\begin{abstract}
Tick paralysis (TP) is a rare disease with rapid progression and potential fatal evolution. Immediately after the diagnosis, removal of all ticks from the body of the patient is mandatory. The present study reports for the first time a human case of the disease in Brazil. The patient had loss of muscle strength, decreased reflexes and marked palpebral ptosis. Six hours after removal of the last tick, the ptosis improved and on the following day, the patient had near total regression of the symptoms. This report emphasizes the possible presence of similar cases that should be promptly diagnosed and quickly treated. A new induction pattern for TP in humans associated with immature stages of ticks is also presented.
\end{abstract}

Key words: tick paralysis, immature ticks, ixodidae.

\section{INTRODUCTION}

Tick paralysis (TP) is an acute disease caused by toxin(s) produced by tick parasitism (1). Such toxin(s) block(s) the neuromuscular system, and usually induce(s) ascending flaccid motor paralysis in a period ranging from hours to a few days, sometimes progressing to respiratory failure and even death (2). TP occurs more frequently in animals and is relatively rare in humans (1). TP in humans (TPH) has been described in Canada, USA, Australia, and sporadically in Europe and Africa $(1,3)$. Recently, Remondegui (4) described two cases of TPH in Argentina that occurred in 1994. The present study reports TPH in Brazil for the first time and highlights unprecedented aspects of the case.

\section{CASE REPORT}

A 28 year-old male medical student was hospitalized in May 2005 complaining of weakness in the upper and lower limbs with difficulty walking and holding objects, tingling fingertips, difficulty keeping the eyes open and visual blurring. Fever and prostration were also recorded. All the symptoms appeared two days before the medical consultation and progressively evolved. He had pruritic erythematous papules on the legs and abdomen, which, according to the patient, were due to infestation by micuins, the popular name of ixodid tick larvae in Brazil (in the country, the most common species belong to the genus Amblyomma) (5).

The patient had already extracted five larvae from his lesions. He reported that he had noticed the ticks four days earlier on his farm in the 
town of Araxá, Minas Gerais State (19³5'34"S, $46^{\circ} 56^{\prime} 27^{\prime \prime} \mathrm{W}$ ), where he had contact with horses, pastures, wetlands, and rivers where capybaras (Hydrochoerus hydrochaeris) were found.

The patient was conscious, well oriented, febrile $\left(38.1^{\circ} \mathrm{C}\right)$ with blood pressure of $125 \times 70$ $\mathrm{mmHg}$, heart rate of $114 \mathrm{bpm}$, and respiratory rate of 28 breaths per minute. We observed 2-3 $\mathrm{mm}$ diameter erythematous papular lesions on the trunk and limbs, and mild bilateral ptosis. Penicillin and doxycycline were prescribed as treatment for suspected leptospirosis or Rocky Mountain spotted fever.

In the evening of admission, the patient complained of intense gastralgia, nausea, and profuse sweating. In the following morning, the patient presented with malaise, muscle weakness, blurred vision, severe bilateral ptosis, dry cough, headache and dysphagia. TP with bulbar involvement was suspected and a new search for immature tick forms led to the identification and removal of one last specimen that was attached to his right inguino-femoral region. Two hours later the patient was admitted to the intensive care unit, presenting dysphagia, decreased muscle strength on the left side (predominantly crural), and overall decreased reflexes, palpebral ptosis, plantar cutaneous reflex was bilaterally indifferent but sensitivity was preserved. Six hours after removal of the last tick, there was no more ptosis.

On the following day, there was near complete regression of the manifestations, the patient had only some degree of lethargy, ataxia, and difficulty finding words for communication that gradually disappeared over 48 hours. Two days after the last immature tick was removed, electromyography showed normal sensory and motor nerve conduction in the distal branches of the sciatic nerves. Biochemical, hematological, and urine parameters were normal. Tests for serologic diagnosis including leptospirosis, Rocky Mountain spotted fever, dengue fever, syphilis, HIV, anti-nuclear antibodies and rheumatoid factor were negative, as were cultures for Rickettsia and common bacteria. Cerebrospinal spinal fluid analysis showed no abnormalities (WBC, biochemistry, smear, culture, and latex test for bacterial and cryptococcal antigens). Brain magnetic resonance imaging was normal. A computed tomography scan of paranasal sinuses showed only bilateral ethmoid sinusitis. It was not possible to identify the tick species and to differentiate its immature stage after removal from the body of the patient. Since then, the patient has remained asymptomatic and with normal neurological exams.

\section{DISCUSSION}

It is estimated that nearly 60 species of ticks cause TP (1). Demacentor andersoni and Demacentor variabilis in North America and Ixodes holocyclus in Australia are the most commonly involved in TPH (1). Currently, in Brazil, 61 tick species are known, 30 of which belong to the genus Amblyomma (6).

In the present case report, considering the location and time of year, it is most likely that the immature specimens were of the genus Amblyomma, probably the species Amblyomma cajennense, common in pastures throughout Brazil (5-9). The occurrence of TPH provoked by the immature tick form has never been reported and it contradicts some other hypotheses on toxin production mechanisms, up to now more related to female ticks $(1,2)$.

The occurrence of paralysis followed by death caused by tick bites of Ixodes species has been observed in rodent species Callomys callosus during the larval feeding period in the laboratory (10). The time between onset of parasitism and signs of paralysis was 2 to 10 days, which agrees with the literature.

Our findings corroborate those of Serra Freire (11), who described TP in Brazil in the 1980s. The author analyzed TP in cattle, sheep, and goats, both naturally and experimentally infested with all developmental stage of Amblyomma cajennense (11). Concerning fever, the clinical condition of our patient was similar to TP cases described in North America rather those of Australia, which were generally more severe and whose recovery was slower after removal of the last tick $(1,12)$. Such outcomes may be explained by similarities in chemical structure and sites of action of toxins.

The occurrence of the disease in autumn, when larvae of many Amblyomma species are in the vegetation, differed from other classic TPH cases reported up to this moment $(7,12)$. Clinical and laboratory results allowed us to exclude differential diagnoses for Guillain-Barré syndrome, botulism, spotted fever, leptospirosis and other diseases. The diagnosis of TPH could be accomplished, so far, only through clinical and 
epidemiological features of the disease, i.e., the presence of rapidly progressive muscle weakness associated with the presence of ticks injecting toxin(s) while sucking blood from the victim.

The hallmark of TPH is its fulminating evolution. In regions where the disease occurs more often, the diagnosis is easier and the search for ticks attached to the patient's body can be done thoroughly and consequently lives can be saved with this simple act. Therefore, it is expected that, in regions where TPH has never been diagnosed, it may go unnoticed and unfortunately deaths may occur. For this reason, this study aims to demonstrate the presence of the TPH in Brazil, where there have been no reported cases in the literature to the best of our knowledge, thus alerting for faster diagnosis and emphasizing the need for complete removal of all ticks to prevent deaths. The identification of this new induction pattern for TP has also drawn attention from other countries including those situated in Neotropical regions and the USA, where massive infestation by larvae of Amblyomma is present (13).

\section{ACKNOWLEDGMENTS}

We would like to thank the special collaboration of Professor Darci Moraes Barros-Battesti, Director of the Laboratory of Parasitology, Butantan Institute, São Paulo, SP, Brazil. Her command of knowledge on ticks was essential to enable us to present a consistent discussion of our case.

\section{COPYRIGHT}

\section{(C) CEVAP 2012}

\section{SUBMISSION STATUS}

Received: May 14, 2012.

Accepted: August 14, 2012.

Abstract published online: September 3, 2012.

Full paper published online: November 30, 2012.

\section{CONFLICTS OF INTEREST}

The authors declare no conflicts of interest.

\section{CONSENT}

Informed consent was obtained from the patient for publication of this case report.

\section{CORRESPONDENCE TO}

Ricardo Augusto Monteiro de Barros Almeida, Departamento de Doenças Tropicais e Diagnóstico por Imagem, Faculdade de Medicina de Botucatu, UNESP, Distrito de Rubião Jr., s/n, Botucatu, SP, 18618-970, Brasil. Phone: +55 143880 1291. Fax: +55 143815 9898. Email: almeidaramb@yahoo.com.br.

\section{REFERENCES}

1. Edlow JA, McGillicuddy DC. Tick paralysis. Infect Dis Clin North Am. 2008;22(3):397-413.

2. Vedanarayanan V, Sorey WH, Subramony SH. Tick paralysis. Semin Neurol. 2004;24(2):181-4.

3. Frimmel S, Löbermann M, Buxton B, Reisinger EC. Abducens nerve palsy following a tick bite: a case report. Int J Med Microbiol. 2006;296(Suppl 40):3045.

4. Remondegui C. Tick paralysis cases in Argentina. Rev Soc Bras Med Trop. 2012;45(4):533-4.

5. Guglielmone AA, Beati L, Barros-Battesti DM, Labruna MB, Nava S, Venzal JM, et al. Ticks (Ixodidae) on humans in South America. Exp Appl Acarol. 2006;40(2):83-100.

6. Dantas-Torres F, Onofrio VC, Barros-Battesti DM. The ticks (Acari: Ixodida: Argasidae, Ixodidae) of Brazil. Syst Appl Acarol. 2009;14:30-46.

7. Labruna MB, Terassini FA, Camargo LM. Notes on population dynamics of Amblyomma ticks (Acari: Ixodidae) in Brazil. J Parasitol. 2009;95(4):1016-8.

8. Serra Freire NM, Sena LM, Borsoi AB. Parasitismo humano por carrapatos na Mata Atlântica, Rio de Janeiro, Brasil. EntomoBrasilis. 2011;4(2):67-72.

9. Serra Freire NM. Occurrence of ticks (Acari: Ixodidae) on human hosts, in three municipalities in the State of Pará, Brazil. Rev Bras Parasitol Vet. 2010;19(3):141-7.

10. Soares JF, Martins TF, Nieri-Bastos FA, Barros-Battesti DM, Labruna M.B. Paralisia causada por Ixodes schulzei Aragão e Fonseca, 1951 (Acari: Ixodidae) em roedores. Anais do XXI Congresso Brasileiro de Parasitologia e II Encontro de Parasitologia de Mercosul; Foz do Iguaçu, Paraná. Rev Patol Trop. 2009. p. 1170.

11. Serra Freire NM. Tick paralysis in Brazil. Trop Anim Hlth Prod. 1983;15(2):124-6.

12. Dworkin MS, Shoemaker PC, Anderson DE. Tick paralysis: 33 human cases in Washington State, 19461996. Clin Infect Dis. 1999;29(6):1435-9.

13. Elston DM. Human infestation by larval Amblyomma ticks. Arch Dermatol. 2006;142(4):497-500. 